$\xi=-1$

\title{
Microwave Pyrolysis of Water hyacinth for Biochar Production Using Taguchi Method
}

\author{
Noor I. Abd ${ }^{1 *}$, Ameel Mohammed Al-Mayah², Shatha K. Muallah ${ }^{3}$ \\ 1,2,3 Department of Biochemical Engineering, Al-Khwarizmi College of Engineering, University of Baghdad, Baghdad, Iraq \\ *Corresponding author E-mail: noorihssan104@yahoo.com
}

\begin{abstract}
The manuscript should contain an abstract. The abstract should be self-contained and citation-free and should not exceed 200 words. The abstract should state the purpose, approach, results and conclusions of the work. The author should assume that the reader has some knowledge of the subject but has not read the paper. Thus, the abstract should be intelligible and complete in it-self (no numerical references); it should not cite figures, tables, or sections of the paper. The abstract should be written using third person instead of first perso The fast microwave assisted pyrolysis (FMWAP) of water hyacinth (WH) for biochar production is investigated. Taguchi's method was used to optimize FMWAP parameters. The effects of microwave power, temperature, microwave absorber (activated carbon) ratio, and biomass particle size on biochar yield as the response for the process, were studied. The maximum yield was achieved using the optimized conditions of microwave power- $994 \mathrm{~W}$; temperature- $300^{\circ} \mathrm{C}$; microwave absorber ratio- 0.25 ; and biomass particle size- $0.0315 \mathrm{~mm}$. The reaction time was kept constant at $2 \mathrm{~min}$. The analysis of Signal to Noise ratio (S/N) and variance (ANOVA) were used to identify the effect and the significance of the process parameters on biochar yield. The final results show the significance of all process parameters on biochar yield. The order of significance of these parameters are: microwave power $>$ temperature $>$ microwave absorber $>$ biomass particle size. The produced biochar was analyzed by scanning electron microscopy (SEM) and Energy Dispersive X-Ray Analyzer (EDX). The WH biochar has macroporous and microporous structure and amorphous in nature with some mineral oxides attached to the surface.
\end{abstract}

Keywords: Water hyacinth, microwave heating, fast pyrolysis, taguchi method, biochar, energy and environment.

\section{Introduction}

Eichhornia crassipes or WH is one of the most common herbaceous aquatic weeds grows in a variety of freshwater habitats: from temporary shallow lagoons, swamps and rivers, to large lakes and reservoirs. The original habitat of this plant is the Amazon River Basin in the South American continent, and it has spread to other many countries in the world especially in the tropics and sub-tropical regions ( $\mathrm{Li}$, et al., 2006). It is one of the most common weeds in the Nile River (Egypt, Kenya, Uganda, Tanzania, and Sudan) and also in the United States of America. It is distributed from the $38^{\circ}$ North Latitude to the $38^{\circ}$ South Latitude, which represents a high temperature range including waters. However, in neutral media it occurs more numerous. Eichhornia crassipes has invaded some lakes located in the urban radius of the city of Concepción due to the sustained nutrient enrichment of these lakes, product of the emptying of a waste of the population located in the environment of these lagoons (Feng, et al., 2017).

The first appearance of $E$. Crassipes in Iraq was in the mid-1980s as a decorative plant imported by the owners of some plantations located to the east of Baghdad. This weed found an environment suitable for spreading across the Tigris River especially in the bays and carrots to the central and southern governorates of Iraq (about $600 \mathrm{~km}$ ) (Mohammed K. 2013)

The existence of this highly invasive species in these areas cause many important risks and environmental problems for the inhabitants of those areas: it affects the quality of water and reduces oxygen content, as a result water becomes invalid environmentally for other native aquatic organisms and promotes the growth of other harmful organisms. This plant consumes large amounts of water, nearly 10 liters of water per day. Impedes navigation through the formation of dense mats of plants interlocking and compact. It prevents the access of sunlight to other organisms in the water, especially phytoplankton, which is the basis of the basic ecosystem and food for animal and fish, causing an imbalance in the delicate food network. Obstruct irrigation operations by closing and preventing the flow of irrigation water in the narrow channels as well as, closing irrigation and drainage pumps. Obstruct irrigation operations by closing and preventing the flow of irrigation water in narrow channels, as well as closing irrigation and drainage pumps. Displacement of local endemic aquatic plants through competition and overcoming them. A significant increase in the amounts of soluble substances resulting from the dead parts of the plant and its fall to the water bottom, which change and disruption of the ecosystem. The presence of this weed has posed a threat to the health of people in these areas, and become a safe haven and shelter for the multiplication of species of flies, mosquitoes, and snails, which carry schistosomiasis, an environment suitable for harboring snakes (Mohammed K. 2013).

As mentioned earlier, there is an urgent need to overcome these problems in order to maintain the ecosystem in these areas on the one hand and take advantage of WH harvest as an interesting biomass with economic benefits on the other hand. So, reuse approach is a feasible way to produce materials that have economic value (Syarif, And Pardede, 2014).

Biomass, like any other renewable energy source, has limitations on its use and applicability and must compete not only with fossil 
fuels but also with other renewable sources such as wind, solar power or tides. Biomass can be converted into useful forms of energy through the use of different technologies. The factors that influence the type of conversion process which will be used are: the type and quantity of raw material, the energy required for the transformation and the legal and economic requirements (Feng, et al., 2017).

Nowadays Todays, biomass pyrolysis has received considerable attention in order to investigate an efficient utilization for bioproducts also it is relatively simple and flexible (Mosa et al., 2018).

Pyrolysis is an efficient bio-change strategy that transom WH into biochar, condensable gases (bio-oil) and non-condensable gases (biogas or pyrolysis gas (Hu et al., 2015), (Rasul et al., 2012). Pyrolysis is the process of thermal decomposition of organic components found in biomass in the absence of oxygen ( $\mathrm{Li}$ et al. 2016).

Biochar is an interesting product that has many potentially attractive applications economically and environmentally (Rasul et al., 2012). The physical and chemical properties of biochar obtained by thermal treatment depend highly on the biomass used and the parameters of the pyrolysis process (Kan et al., 2016). It contains many nutrients that plants need, making it eligible as a soil improver. It contains several nutrients that plants need, making it eligible as soil improver. At the same time, it can act as a carbon capture medium to reduce carbon dioxide emissions in the atmosphere. The concentration of nutrients in biochar varies depending on the biomass used and the pyrolysis parameters (Shalini et al., 2017). The transformation of WH to biochar by pyrolysis can be achieved by two ways: the conventional pyrolysis and the fast microwave assists pyrolysis. The fast microwave assisted pyrolysis (FMWAP) is an attractive versatile induced pyrolysis process, where conditions can be adjusted to produce the most suitable product. Additionally, the energy consumption is 1.5 times more efficient than the corresponding conventional process (Budarin et al., 2011) It is controllable energy and cost efficient, therefore it has wide applications in the pilot scale and the industrial scale (Mašek et al., 2013).

Literature review: Few studies have been published on the conversion of WH to coal using FMWAP or conventional pyrolysis. Mosa et al., 2018, evaluate the efficacy of biochar produced by conventional slow pyrolysis process $\left(\right.$ at $450^{\circ} \mathrm{C}$ ) from water hyacinth plants grown in synthetic contaminated water. They study the isothermal and kinetics modeling of phosphate sorption data The functionalized biochars (i.e. rich heavy metal content) was found unfunctionalized forms.

Li et al., 2016, investigate the removal of cadmium from aqueous solutions using biochars derived from water hyacinth were collected from a stream in Nansha District, Guangzhou, China. These biochars were prepared by the slow pyrolysis method for $2 \mathrm{hrs}$ and at $300^{\circ} \mathrm{C}, 500^{\circ} \mathrm{C}$ and $700^{\circ} \mathrm{C}$. They found that E. crassipes biochars exhibit good removal adsorbent for wastewater treatment. The maximum adsorption for cadmium by precipitation or coprecipitation were $49.837,36.899$, and $25.826 \mathrm{mgg}^{-1}$.

High improvement to the soil biological activity was found by Masto et al., 2013, using biochar derived from pyrolyzed WH by conventional heating method. The optimum condition for biochar was $300-350^{\circ} \mathrm{C}$ temperature with $30-40$ min residence time. They found that the microbial activity increased 3 times and the soil respiration 1.9 times. The efficiency and mechanism of adsorption on phosphate from aqueous solutions using magnetic Fe oxidebiochar nanocomposite derived from water hyacinth were investigated by Cai et al., 2017. They used conventional heating method to prepare the $\mathrm{Fe}$ oxide-biochar. They found that $\mathrm{Fe}$ oxide-biochar pyrolyzed at $450^{\circ} \mathrm{C}$ exhibited a promising alternative for phosphate removal from most eutrophic waters with sorption capacity was estimated to be $5.07 \mathrm{mgg}^{-1}$.

The main objective of this study is to produce biochar from WH using FMWAP. To achieve this goal, (1) the operating conditions of FMWAP are optimized to maximize the yield of biochar, (2) using an appropriate design for the experiments, and (3) characterize various the physiochemical properties of biochar. The effects of microwave power, temperature, microwave absorber ratio (activated carbon), and biomass particle size on biochar as a response, were studied. FMWAP process parameters optimization was performed using Taguchi method. The analysis of signal to noise ratio $(\mathrm{S} / \mathrm{N})$ was used to predict the optimum condition and the identify effects of process parameters. The degree of significance of the process parameters on biochar yield was performed using the Analysis of Variance (ANOVA), respectively.

\section{Materials and Methods}

Raw material: Eichhornia Crassipes or WH was used as a raw material for microwave pyrolysis process. The samples of this plant were collected from the banks of Tigris River in the Abu Nuwas District, Baghdad, Iraq. The samples were first washed with tab water and then with distilled water to remove any suspended particles. WH samples were dried at $105^{\circ} \mathrm{C}$ for $24 \mathrm{~h}$, crushed by disk mill, sieved into the following fractions of particle sizes $(1-2 \mathrm{~mm}),(355 \mu \mathrm{m}-1 \mathrm{~mm}),(63-355 \mu \mathrm{m})$, and $<63 \mu \mathrm{m}$, and stored in a desiccator until use. The average size for each range was adopted in this study.

Microwave absorber: Activated Carbon (AC) was used as a microwave absorber. The properties of AC are shown in Table 1.

Table 1: The properties of activated carbon as a microwave absorber.

\begin{tabular}{|l|l|}
\hline Parameter & Value \\
\hline Appearance & A fine black powder \\
\hline solubility & Insoluble in water \\
\hline pH & $6-7.5$ \\
\hline Methylene blue adsorption (0.15\% solution) & $18 \mathrm{ml} / 0.1 \mathrm{~g}$ \\
\hline Loss on drying (at 105C for two hours) & $5 \%$ \\
\hline Ash & $2.5 \%$ \\
\hline Acid soluble & $2.5 \%$ \\
\hline Water soluble & $1.5 \%$ \\
\hline Particle size passing through 300 mesh & Min. $60 \%$ \\
\hline CDH, India & \\
\hline
\end{tabular}

Pyrolysis reactor: The pyrolysis reactor is a quartz tube of 140 $\mathrm{ml}$ volume. Two streams are connected to the reactor, one for introducing $\mathrm{N}_{2}$ gas and the other one for withdrawing the gaseous product. The $\mathrm{N}_{2}$ (99.999 vol.\%) gas was introduced to the reactor to the lower point of the reactor in order to ensure good heat distribution. A thermocouple type $\mathrm{K}$ was used to read the temperature inside the reactor. This sensor was mounted in an appropriate way to read the temperature at the center of the biomass bed.

The FMWAP pyrolysis experiments were performed in a laboratory unit developed in University of Baghdad (Fig. 1). It consists of the following main parts; $\mathrm{N}_{2}$ gas cylinder, $\mathrm{N}_{2}$ gas pressure regulator, microwave oven, pyrolysis reactor, trap for tar collection, vapour condenser, liquid collector, cooling device and data acquisition device for temperature readings. This device is connected to a laptop. 50 vol. \% ethanol-water liquid was used as a cooling medium in the cooling device and circulated in the vapour condenser and liquid collector.

The microwave source was a modified household microwave oven (10 liter volume and type LG, Chaina, MH943SAR). As a microwave generator, a magnetron with a working frequency of 2.45 $\mathrm{GHz}$ and with a maximum power of $1250 \mathrm{~W}$ was used. The output power of the electromagnetic waves is adjusted by varying the power voltage of the magnetron. Only quartz tube of the pyrolysis reactor was introduced to the microwave chamber through a hole at the top of the chamber, while the remaining parts are placed outside the chamber. 




Fig.1: The process flow diagram of a laboratory microwave pyrolysis unit.

Physical properties of WH: WH biomass moisture content was determined by a standard oven drying method (Cai et al., 2017). The ash content was estimated according to NREL/TP-510-42622 method.

Chemical properties of WH: The chemical properties of WH biomass are lignin, cellulose and hemicellulose content. Lignin content was determined according to modified methods of Goering and Van Soest (1971) (Sluiter et al.,2016). Cellulose content was determined by ADF method. Hemicellulose content was estimated according to method of Goering and Van Soest (1970), and Van Soest, Robertson and Lewis (1991) (Shoyakubov, and Aitmetova, 1999).

Characterization of WH biochar: The analysis of surface morphology of biochars lsamples were performed by using Scanning Electron Microscopy (SEM) (FEI Company, Inspect S50, Netherlands). This device is equipped with Energy Dissipative X-ray spectroscopy (EDX) (Brucker Company- X flash 6L10, Germany). The chromatographic peaks are identified and analyzed by means of the standard spectral data library.

Experimental design using Taguchi method: The design of WH pyrolysis experimental conditions using FMWAP was performed using Taguchi method. The effect of microwave power (percent of microwave power from the actual value $1250 \mathrm{~W}$ ), temperature, microwave absorber ratio (microwave absorber to biomass weight ratio) and biomass particle size were studied. The reaction time was kept constant at 2 min. Taguchi $L_{16}$ array was used as the orthogonal array for the experimental design. The control factors (i.e. process parameters) and their levels are listed (Table 2). The experimental flow diagram of Taguchi approach was described (Fig. 2). First, the microwave pyrolysis unit was constructed and experiments were set up. Problem formulation by selecting the objective function, factors and levels, then utilizing Taguchi method for estimating the appropriate orthogonal array and designing the pyrolysis experiments. The signal-to-noise ratio is one of the significant contributions of the Taguchi method for the experimental design. The effects of the factors/levels on yield were estimated using $S / N$ ratio and the final response table was constructed. Optimization of WH microwave pyrolysis conditions was also performed. The experimental results were also analyzed with the analysis of variance (ANOVA) to find the significance of the process factors. A confidence level of $95 \%$ was used to evaluate the significance of the operating factors on the biochar yield. MINITAB 17 (Mintab Inc., PA, USA) software was used to generate the experimental design for the robust design technique of Taguchi and perform the analysis of S/N ratio and ANOVA analysis.

Table 2: Control factors and their levels.

\begin{tabular}{|l|c|c|c|c|}
\hline \multirow{2}{*}{ Operating factors } & \multicolumn{2}{|c|}{ Levels } & \multicolumn{3}{l|}{} \\
\cline { 2 - 5 } & 1 & 2 & 3 & 4 \\
\hline Microwave power $(\mathrm{MW}),(\mathrm{W})$ & 0.8 & 0.86 & 0.9 & 0.95 \\
\hline Temperature (Temp.), $\left({ }^{\circ} \mathrm{C}\right)$ & 300 & 480 & 580 & 680 \\
\hline
\end{tabular}

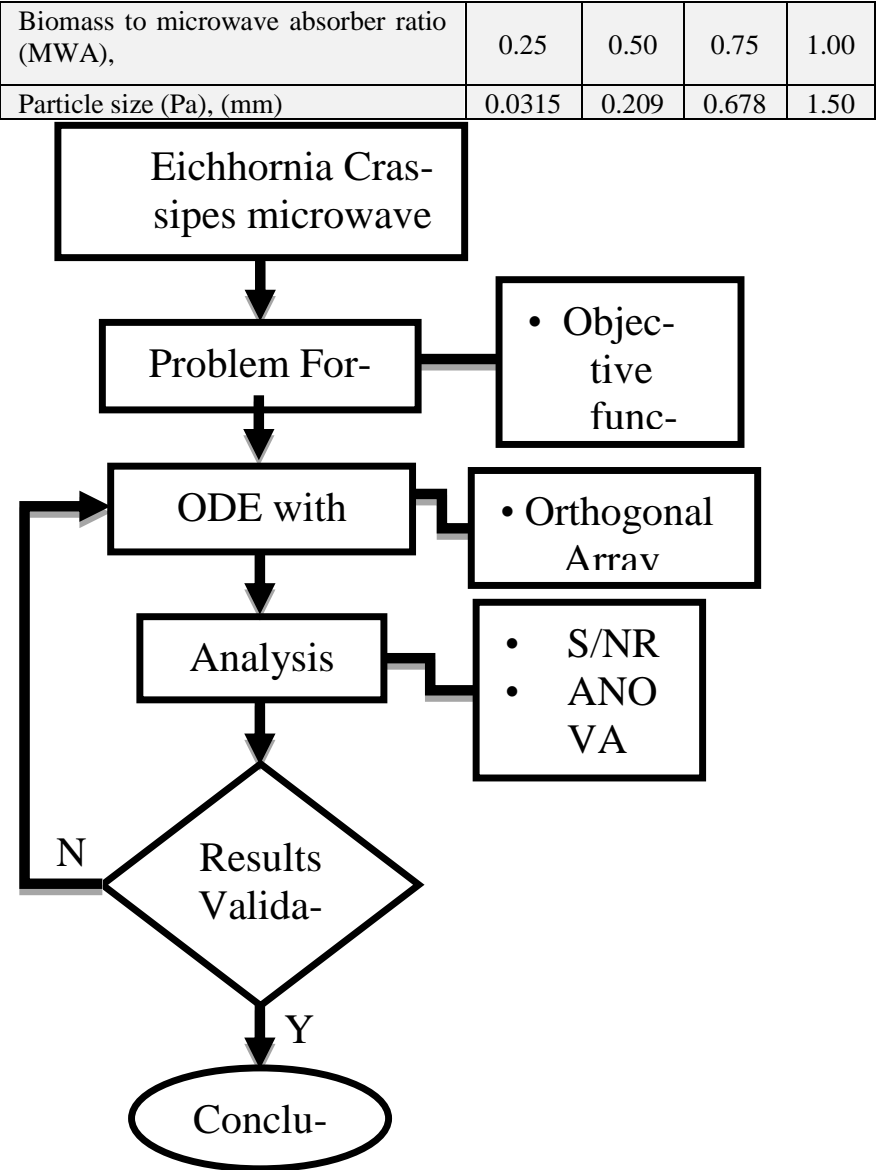

Fig. 2: Flow diagram of Taguchi approach.

\section{Results and Discussions}

The physicochemical properties of WH: The chemical composition was calculated based on 5\% dry weight (Table 3). It can be observed that the lignocellulosic composition of the biomass arranged in the following order Cellulose> Lignin> Hemicelluloses. These results are consistent with other studies (Feng et al., 2017), (Zaklouta et al., 2011), (Istirokhatun et al., 2015) and (Arjenaki et al., 2012). Some small variations may be noticed between the present the published results in the literature, which in turn indicate the difference in the environment in which WH grows.

Table 3: The physicochemical properties of WH.

\begin{tabular}{|l|l|}
\hline component & (wt.\%) \\
\hline Ash content & 1.000 \\
\hline Lignin content & 23.45 \\
\hline Cellulose content & 30.60 \\
\hline Hemicelluloses content & 15.10 \\
\hline Moisture content & 95 \\
\hline
\end{tabular}

Effects of microwave pyrolysis operating conditions on synthetic gas yield: The Taguchi design of experiments for microwave pyrolysis of $\mathrm{WH}$ with the experimental yield of biochar as the response of the process was listed (Table 4).

Table 4: Experimental Taguchi orthogonal array and response of WH microwave pyrolysis experiments.

\begin{tabular}{|c|c|c|c|c|c|}
\hline \multirow{2}{*}{$\begin{array}{c}\text { Run } \\
\text { No. }\end{array}$} & \multicolumn{4}{|c|}{ Operating parameters } & Response \\
\cline { 2 - 6 } & MW power (\%) & $\begin{array}{c}\text { Temp. } \\
\left({ }^{\circ} \mathrm{C}\right)\end{array}$ & $\begin{array}{c}\text { MWA ratio } \\
(-)\end{array}$ & $\begin{array}{c}\mathrm{P}_{\mathrm{A}} \\
(\mathrm{mm})\end{array}$ & $\begin{array}{c}\text { Synthetic gas } \\
\text { yield (wt.\%) }\end{array}$ \\
\hline $\mathbf{1}$ & 0.80 & 300 & 0.25 & 1.500 & 0.04909 \\
\hline $\mathbf{2}$ & 0.80 & 480 & 0.50 & 0.678 & 0.09796 \\
\hline $\mathbf{3}$ & 0.80 & 580 & 0.75 & 0.209 & 0.09995 \\
\hline
\end{tabular}




\begin{tabular}{|l|l|l|l|l|l|}
\hline $\mathbf{4}$ & 0.80 & 680 & 1.00 & 0.032 & 0.17441 \\
\hline $\mathbf{5}$ & 0.86 & 300 & 0.50 & 0.209 & 0.09838 \\
\hline $\mathbf{6}$ & 0.86 & 480 & 0.25 & 0.032 & 0.26609 \\
\hline $\mathbf{7}$ & 0.86 & 580 & 1.00 & 1.500 & 0.04919 \\
\hline $\mathbf{8}$ & 0.86 & 680 & 0.75 & 0.678 & 0.28261 \\
\hline $\mathbf{9}$ & 0.90 & 300 & 0.75 & 0.032 & 0.07947 \\
\hline $\mathbf{1 0}$ & 0.90 & 480 & 1.00 & 0.209 & 0.26603 \\
\hline $\mathbf{1 1}$ & 0.90 & 580 & 0.25 & 0.678 & 0.30504 \\
\hline $\mathbf{1 2}$ & 0.90 & 680 & 0.50 & 1.500 & 0.17411 \\
\hline $\mathbf{1 3}$ & 0.95 & 300 & 1.00 & 0.678 & 0.26496 \\
\hline $\mathbf{1 4}$ & 0.95 & 480 & 0.75 & 1.500 & 0.21819 \\
\hline $\mathbf{1 5}$ & 0.95 & 580 & 0.50 & 0.032 & 0.44215 \\
\hline $\mathbf{1 6}$ & 0.95 & 680 & 0.25 & 0.209 & 0.57579 \\
\hline
\end{tabular}

Analysis of signal to noise ratio: Table 5 shows the values of $\mathrm{S} / \mathrm{N}$ ratio for the experimental array (Table 4). The Larger is Better for $S / N$ values was used to optimize the operating conditions also to identify the effect of each factor on the pyrolysis process response. The highest value of $\mathrm{S} / \mathrm{N}$ ratio identify the control factor that minimize the effect of the noise factors and maximize the value of response. The value of $\mathrm{S} / \mathrm{N}$ was calculated using the following equations (Zirehpour et al., 2014):

$S / N=-10 \log _{10}\left(\frac{1}{\text { MSD }}\right)$

$M S D=\frac{1}{n}\left(\sum_{i=1}^{n} Y_{i}^{2}\right)$

Where, $Y_{i}$ is the response for the experiment, and $n$ is the number of runs.

The effect of each control factor and their levels on the synthetic gas yield is explained in Table 6 . This table contians the values of $\mathrm{S} / \mathrm{N}$ ratio for each level of each factor. Also, this table includes ranks based on delta statistics. This property compares the relative magnitude of effects, which can be estimated as the highest average for each factor minus the lowest average for the same. Rank 1 assigned for the highest delta value while rank 5 assined for the lowest delta value, and so on for the remaining values. It can be observed that the effect of factors is arranged in the following rank: microwave power (rank 1)> Temperature> microwave absorber ratio> biomass particle size (rank 4).

The main effect plot is used to determine the maximum value of the response. The highest value of $\mathrm{S} / \mathrm{N}$ ratio for biochar yield refers to the maximum value for a given factor (Fig. 3). It can be observed that with increasing the power of microwave energy, more energy absorbs by the biomass which in turn degraded into more volatile and light products. Table 2 shows that the chemical composition of the WH biomass. It can be noticed the high content of cellulose and the low content of lignin. At high microwave energy cellulose compounds tend to pyrolyzed more to light and volatile products. So that, a high yield is obtained at lower microwave power. These findings agree well with the results reported in the literature (Januri et al., 2017), (Zhang et al., 2017), and (Demirbas, 2004). The effect of temperature has the same effect of microwave power. The same explanation can be adopted for the effect of temperature on biochar yield.

The addition of microwave absorbent to the biomass greatly increase the dielectric properties of the biomass, in turn, enhance the pyrolysis rate and effect the pyrolysis reactions. This phenomenon can be shown in Fig. 5. The biochar yield increase with the increase in activated carbon to biomass ratio and reached its maximum value at 0.75 ratio. The microwave absorber speeds up the heating rate of biomass particles. Further increase in absorber ratio leads to a decrease of biochar yield due to the formation of more light products. The same observations were found by many re- searchers (Shen, 2009), (Januri et al., 2017), and (Zhang et al., 2017). Also, Huang et al., 2016, and Shen, 2009 found that the type and quantity of metallic oxides in biochar supported metallic catalysts greatly affect the yields of biochar, biogas, and biooil.

Biomass particle size is another important parameter in FMWAP process. WH biochar yield increased with the increase in $\mathrm{WH}$ biomass particle size and as indicated by the values of $\mathrm{S} / \mathrm{N}$ ratio (Fig. 3). This result is consistent with other results reported by (Shen, 2009), (Demirbas, 2004), and (Crombie et al., 2013) who found that biochar yield increased with the increased the biomass particle size. They concluded that with smaller particle size the heating rate will be rapidly and instantly. As a result, the biomass degrades faster to light products and verse versa.



Fig. 3: Main effects plot of operating parameters on $\mathrm{S} / \mathrm{N}$ ratio of synthetic gas yield.

Table 5: $\mathrm{S} / \mathrm{N}$ for the observed values of products

\begin{tabular}{|l|l|c|}
\hline & Synthetic gas & \\
\hline Run No. & Variance(-) & S/N ratio (-) \\
\hline $\mathbf{1}$ & & -26.18 \\
\hline $\mathbf{2}$ & & -20.18 \\
\hline $\mathbf{3}$ & & -20 \\
\hline $\mathbf{4}$ & & -15.17 \\
\hline $\mathbf{5}$ & & -20.46 \\
\hline $\mathbf{6}$ & & -11.5 \\
\hline $\mathbf{7}$ & & -26.16 \\
\hline $\mathbf{8}$ & & -10.98 \\
\hline $\mathbf{9}$ & & -22 \\
\hline $\mathbf{1 0}$ & & -11.5 \\
\hline $\mathbf{1 1}$ & & -10.31 \\
\hline $\mathbf{1 2}$ & & -15.18 \\
\hline $\mathbf{1 3}$ & & -11.54 \\
\hline $\mathbf{1 4}$ & & -13.22 \\
\hline $\mathbf{1 5}$ & & -7.089 \\
\hline $\mathbf{1 6}$ & & -4.795 \\
\hline
\end{tabular}

Table 6: Response table for $\mathrm{S} / \mathrm{N}$ of synthetic gas yield.

\begin{tabular}{|l|l|l|l|l|}
\hline Level & MW ratio & T. ${ }^{\circ} \mathrm{C}$ & MWA ratio & $\mathrm{Pa}(\mathrm{mm})$ \\
\hline 1 & -20.383 & -20.043 & -13.197 & -13.938 \\
\hline 2 & -17.275 & -14.101 & -15.728 & -14.19 \\
\hline 3 & -14.748 & -15.892 & -16.55 & -13.251 \\
\hline 4 & -9.161 & -11.531 & -16.092 & -20.187 \\
\hline Delta & 11.222 & 8.513 & 3.353 & 6.936 \\
\hline Rank & 1 & 2 & 4 & 3 \\
\hline
\end{tabular}

WH microwave pyrolysis process optimization: The highest values (i.e. the optimum values) of microwave power- $79.5 \%$, temperature- $300^{\circ} \mathrm{C}$, microwave absorber ratio- $25 \%$, and particle size $-0.0135 \mathrm{~mm}$ (Fig.4). 


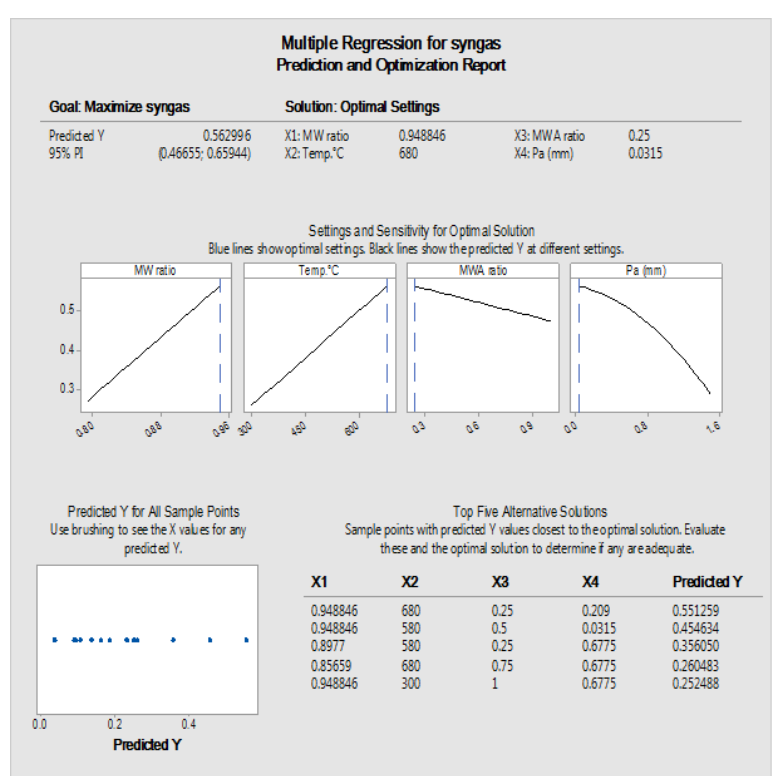

Fig. 4: The optimum operating conditions of microwave pyrolysis of WH biomass to produce synthetic gas.

Analysis of Variance (ANOVA): An analysis of the variance allows to determine if different treatments show significant differences or not. The importance of analysis of variance is diagnosed the significance of design factors on the responses of the process. ANOVA table involves the F-statistic value $(F)$ with its p-value, which identify the significance of process factors on the products $\mathrm{P}$-value is the probability of obtain $\mathrm{F}$ value that is must be as extreme as the experimental value. P-value used to test the hypothesis and to know when to reject or refuse to reject the null hypothesis. If the p-value $<0.05$ (with confidence level 95\%) the null hypothesis reject is refused and on the other hand the design variables are significant (Wang, 2012). Analysis of Variance (ANOVA) of biochar yield is tabulated in Table 7. In this table, it can be observed that the values of $\mathrm{P}$ for all the factors are less than 0.05 , and F-values are larger than 4 . This means that all the factors have significance effect on the WH microwave pyrolysis. The percentage contribution for each parameter defined as the portion of total observed variance in the experiment for each significant parameter. When the value of this percentage contribution is greater, then factor contribution to the final results more than other factors (Zirehpour et al., 2014). It can be observed that the order of contribution is arranged in the following order: Microwave power> Temperature > microwave absorber ratio > biomass particle size.

Table 7: ANOVA for biochar yield of WH microwave pyrolysis process.

\begin{tabular}{|c|c|c|c|c|c|c|c|}
\hline 8 & $\begin{array}{l}\mathrm{D} \\
\mathrm{F}\end{array}$ & $\begin{array}{l}\text { Seq. } \\
\text { SS }\end{array}$ & $\begin{array}{l}\text { Contribu- } \\
\text { tion }\end{array}$ & $\begin{array}{l}\text { Adj. } \\
\text { SS }\end{array}$ & $\begin{array}{l}\text { Adj. } \\
\text { MS }\end{array}$ & $\begin{array}{l}\text { F- } \\
\text { Value }\end{array}$ & $\begin{array}{l}\text { P- } \\
\text { Value }\end{array}$ \\
\hline$\sum_{\Sigma}^{2}$ & - & $\begin{array}{l}\overrightarrow{0} \\
\stackrel{+}{0} \\
\stackrel{0}{0}\end{array}$ & $\begin{array}{l}\stackrel{0}{m} \\
\text { ஸे } \\
\dot{q}\end{array}$ & $\begin{array}{l}\overline{6} \\
\stackrel{+}{0} \\
\\
0\end{array}$ & $\begin{array}{l}\frac{0}{0} \\
0 \\
\text { 嵓 } \\
0 \\
0\end{array}$ & $\begin{array}{l}\tilde{O} \\
\infty \\
\dot{q} \\
\end{array}$ & $\begin{array}{l}8 \\
\vdots \\
0\end{array}$ \\
\hline 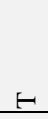 & - & $\begin{array}{l}\stackrel{\infty}{0} \\
\stackrel{0}{0}\end{array}$ & $\begin{array}{l}\stackrel{0}{~} \\
\text { ले } \\
\text { ले }\end{array}$ & \begin{tabular}{l}
$\stackrel{0}{\circ}$ \\
\multirow{0}{0}{} \\
0
\end{tabular} & \begin{tabular}{l}
\multirow{2}{2}{} \\
$\infty$ \\
0 \\
$\vdots$ \\
0
\end{tabular} & $\begin{array}{l}n \\
\dot{z} \\
\dot{y}\end{array}$ & $\begin{array}{l}8 \\
\vdots \\
0\end{array}$ \\
\hline$\sum_{\Sigma}^{\ll}$ & - & 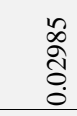 & 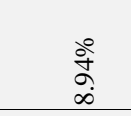 & 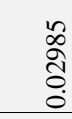 & $\begin{array}{l}\text { वे } \\
\infty \\
\stackrel{ి}{0} \\
\stackrel{0}{0}\end{array}$ & $\begin{array}{l}2 \\
= \\
=\end{array}$ & $\begin{array}{l}5 \\
0 \\
0\end{array}$ \\
\hline$\overleftrightarrow{\iota}$ & - & $\begin{array}{l}\text { r. } \\
\infty \\
0 \\
0 \\
0 \\
0\end{array}$ & $\begin{array}{l}\frac{0}{6} \\
\infty \\
\infty\end{array}$ & 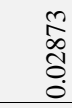 & 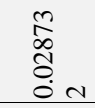 & 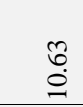 & $\begin{array}{l}\infty \\
0 \\
0\end{array}$ \\
\hline 壹 & $=$ &  & $\begin{array}{l}\grave{2} \\
\vdots \\
\infty \\
\infty\end{array}$ &  & $\begin{array}{l}\stackrel{2}{\widehat{a}} \\
\stackrel{8}{0} \mathrm{~N}\end{array}$ & & \\
\hline
\end{tabular}



Fig. 5: SEM images of WH biochar.

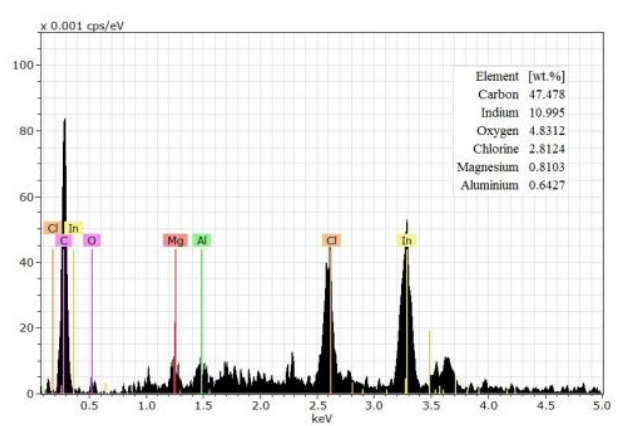

Fig. 6: EDX spectra of WH biochar.

\section{Conclusions:}

Biochar was produced from WH. The effect of FMWAP process factors/levels on biochar yield was studied. The pyrolysis experiments were conducted using Taguchi experimental design (L16 orthogonal array). The analysis of $\mathrm{S} / \mathrm{N}$ ratio show that order of effects of process parameters are arrange in the following rank: microwave power (rank 1)> Temperature> microwave absorber ratio> biomass particle size (rank 4). The analysis of ANOVA for biochar yield show that all the process factors have significance effect on the WH microwave pyrolysis. Also, the percentage contribution for each factor to the final results is arranged in the following order: Microwave power> Temperature> microwave absorber ratio> biomass particle size. The optimum conditions for the maximum biochar yield were: microwave power ratio-, temperature $-300^{\circ} \mathrm{C}$, microwave absorbed ratio- 0.75 and biomass particle size- $0.15 \mathrm{~mm}$. The maximum WH biochar yield at the optimum conditions was $95 \%$. The analysis of SEM/ EDX shows that the WH biochar is macroporous structure, amorphous in nature with some local mineral oxides. The result of the present study show that WH is a good precursor for biochar production. 


\section{References}

[1] Arjenaki, F. G., Jabbari, R., \& Morshedi, A. (2012). Evaluation of drought stress on relative water content, chlorophyll content and mineral elements of wheat (Triticum aestivum L.) varieties. International Journal of Agriculture and Crop Sciences, 4(11):726-729.

[2] Budarin, V. L., Shuttleworth, P. S., Dodson, J. R., Hunt, A. J., Lanigan, B., Marriott, R., ... \& Sin, E. H. (2011). Use of green chemical technologies in an integrated biorefinery. Energy \& Environmental Science, 4(2):471-479.

[3] Cai, R., Wang, X., Ji, X., Peng, B., Tan, C., \& Huang, X. (2017) Phosphate reclaim from simulated and real eutrophic water by magnetic biochar derived from water hyacinth. Journal of environmental management, 187:212-219.

[4] Crombie, K., Mašek, O., Sohi, S. P., Brownsort, P., \& Cross, A. (2013). The effect of pyrolysis conditions on biochar stability as determined by three methods. Gcb Bioenergy, 5(2):122-131.

[5] Demirbas, A. (2004). Effects of temperature and particle size on bio-char yield from pyrolysis of agricultural residues. Journal of analytical and applied pyrolysis, 72(2):243-248

[6] Feng, W., Xiao, K., Zhou, W., Zhu, D., Zhou, Y., Yuan, Y. \& Zhao, J. (2017). Analysis of utilization technologies for Eichhornia crassipes biomass harvested after restoration of wastewater. Bioresource technology, 223:287-295.

[7] Guo, F., Liu, Y., Liu, Y., \& Guo, C. (2017). Catalytic reforming of tar using corncob char and char-supported potassium catalysts. Journal of Thermal Analysis and Calorimetry, 130(3):12971306.

[8] Hu, Z., Ma, X., \& Li, L. (2015). Optimal conditions for the catalytic and non-catalytic pyrolysis of water hyacinth. Energy Conversion and Management, 94, 337-344.Huang, Yu Fong, Pei Te Chiueh, and Shang Lien Lo. 2016. "A Review on Microwave Pyrolysis of Lignocellulosic Biomass.” Sustainable Environment Research 26 (3). Elsevier Ltd: 103-9.

[9] Istirokhatun, T., Rokhati, N., Rachmawaty, R., Meriyani, M., Priyanto, S., \& Susanto, H. (2015). Cellulose isolation from tropical water hyacinth for membrane preparation. Procedia Environmental Sciences, 23, 274-281.

[10] Januri, Z., Idris, S. S., Akhawan, H. A., Rahman, N. A., Matali, S., \& Manaf, S. F. A. (2017). Effect of mass loading and microwave absorber application method on the product from microwave assisted pyrolysis of palm oil mill effluent. Malaysian Journal of Analytical Sciences, 21(2):470-483.

[11] Kan, T., Strezov, V., \& Evans, T. J. (2016). Lignocellulosic biomass pyrolysis: A review of product properties and effects of pyrolysis parameters. Renewable and Sustainable Energy Reviews, 57:1126-1140.

[12] Li, J., Dai, J., Liu, G., Zhang, H., Gao, Z., Fu, J., .\& Huang, Y. (2016). Biochar from microwave pyrolysis of biomass: A review. Biomass and Bioenergy, 94: 228-244.

[13] Li, W., Wang, B., \& Wang, J. (2006). Lack of genetic variation of an invasive clonal plant Eichhornia crassipes in China revealed by RAPD and ISSR markers. Aquatic Botany, 84(2):176-180.

[14] Mašek, O., Budarin, V., Gronnow, M., Crombie, K., Brownsort, P., Fitzpatrick, E., \& Hurst, P. (2013). Microwave and slow pyrolysis biochar-Comparison of physical and functional properties. Journal of Analytical and Applied Pyrolysis, 100: 41-48.

[15] Masto, R. E., Kumar, S., Rout, T. K., Sarkar, P., George, J., \& Ram, L. C. (2013). Biochar from water hyacinth (Eichornia crassipes) and its impact on soil biological activity. Catena, 111: 64-71.

[16] Mohammed K. (2013), "Water Hyascinth Echhorina crassipes (Martius) in Iraq," Al-Ustath jeanery 206: 216-220, Iraq Natural History Research Centre and Musem- university of Baghdad, Bab AL- Muadham.

[17] Mosa, A., El-Ghamry, A., \& Tolba, M. (2018). Functionalized biochar derived from heavy metal rich feedstock: Phosphate recovery and reusing the exhausted biochar as an enriched soil amendment. Chemosphere, 198:351-363

[18] Rasul, M. G., \& Jahirul, M. I. (2012). Recent developments in biomass pyrolysis for bio-fuel production: Its potential for commercial applications. Central Queensland University, Centre for Plant and Water Science, Faculty of Sciences, Engineering and Health.

[19] Shalini, R., Pugalendhi, S., Subramanian, P., \& Gopal, N. O. (2017). Characteristic study on biochar production from biological substrates by slow pyrolysis for carbon sequestration. Int. J. Curr. Microbiol. App. Sci, 6(4):314-323.
[20] Shen, J., Wang, X. S., Garcia-Perez, M., Mourant, D., Rhodes, M. J., \& Li, C. Z. (2009). Effects of particle size on the fast pyrolysis of oil mallee woody biomass. Fuel, 88(10):1810-1817.

[21] Shen, Y., \& Yoshikawa, K. (2013). Recent progresses in catalytic tar elimination during biomass gasification or pyrolysis-A review. Renewable and Sustainable Energy Reviews, 21, 371-392.

[22] Shoyakubov, R. S., \& Aitmetova, K. I. (1999). Chemical composition of Eichhornia crassipes and Pistia stratiotes. Chemistry of natural compounds, 35(2): 227-228.

[23] Sluiter, A., Sluiter, J., Wolfrum, E., Reed, M., Ness, R., Scarlata, C. \& Henry, J. (2016). Improved methods for the determination of drying conditions and fraction insoluble solids (FIS) in biomass pretreatment slurry. Biomass and Bioenergy, 91: 234-242.

[24] Syarif, N., \& Pardede, M. C. (2013). Hydrothermal assisted microwave pyrolysis of water hyacinth for electrochemical capacitors electrodes. Concrete Structures in Thailand Hydrothermal Assisted Microwave Pyrolysis of Water Hyacinth for Electrochemical Capacitors Electrodes Group Technology Paves the Road for Automation Effect of Laser Priming on Accumulation of Free Proline in Spring, 95.

[25] Wang, Y. Q., Byun, J. H., Kim, B. S., Song, J. I., \& Chou, T. W. (2012). The use of Taguchi optimization in determining optimum electrophoretic conditions for the deposition of carbon nanofiber on carbon fibers for use in carbon /epoxy composites. Carbon, 50(8):2853-2859.

[26] Yu, J., Jiang, C., Guan, Q., Ning, P., Gu, J., Chen, Q., ... \& Miao, R. (2018). Enhanced removal of Cr (VI) from aqueous solution by supported $\mathrm{ZnO}$ nanoparticles on biochar derived from waste water hyacinth. Chemosphere, 195:632-640

[27] Zaklouta, M., Hilali, M., Nefzaoui, A., \& Haylani, M. (2011). Animal nutrition and product quality laboratory manual. ICARDA, Aleppo, Syria. viii.

[28] Zhang, X., Rajagopalan, K., Lei, H., Ruan, R., \& Sharma, B. K. (2017). An overview of a novel concept in biomass pyrolysis: microwave irradiation. Sustainable Energy \& Fuels, 1(8): 1664-1699.

[29] Zirehpour, A., Rahimpour, A., Jahanshahi, M., \& Peyravi,M.(2014).Mixed matrix membrane application for olive oil wastewater treatment: Process optimization based on Taguchi design method. Journal of environmental management, 132:113-120.

[30] Author,"Title of the Paper", Journal name, Vol.X, No.X, (200X), pp.XX-XX, available online: http://xxx, last visit:28.02.2013

[31] Author,"Title of the Paper", Proceedings of the conference name, Vol.X, No.X, (200X), pp:XX-YY, http://dx.doi.org/10.1109/MMM.2013.2248651

[32] Author, Title of the Book, Publisher, (200X), pp:XXX-YYY

[33] Cho JH, Chang SA, Kwon HS, Choi YH, KoSH, Moon SD, Yoo SJ, Song KH, Son HS, Kim HS, Lee WC, Cha BY, Son HY \& Yoon $\mathrm{KH}$ (2006), Long-term effect of the internet-based glucose monitoring system on HbA1c Reduction and glucose stability: a 30-month follow-up study for diabetes management with a ubiquitous medical care system. Diabetes Care 29, 2625-2631.

[34] Fauci AS, Braunwald E, Kasper DL \& Hauser SL (2008), Principles of Harrison's Internal Medicine, Vol. 9, 17thedn. McGraw-Hill New York, NY, pp.2275-2304.

[35] Kim HS \& Jeong HS (2007), A nurse short message service by cellular phone in type-2 diabetic patients for six months. Journal of Clinical Nursing 16, 1082-1087.

[36] Lee JR, Kim SA, Yoo JW \& Kang YK (2007), The present status of diabetes education and the role recognition as a diabetes educator of nurses in korea. Diabetes Research and Clinical Practice 77, 199_ 204.

[37] McMahon GT, Gomes HE, Hohne SH, Hu TM, Levine BA \& Conlin PR (2005), Web-based care management in patients with poorly controlled diabetes. Diabetes Care 28, 1624-1629.

[38] Thakurdesai PA, Kole PL \& Pareek RP (2004), Evaluation of the quality and contents of diabetes mellitus patient education on Internet. Patient Education and Counseling 53, 309-313. 